\title{
Erratum to: Predation by zooplankton \\ on Batrachochytrium dendrobatidis: biological control of the deadly amphibian chytrid fungus?
}

\author{
Julia C. Buck • Lisa Truong • Andrew R. Blaustein
}

Published online: 23 September 2011

(c) Springer Science+Business Media B.V. 2011

\section{Erratum to: Biodivers Conserv (2011) DOI 10.1007/s10531-011-0147-4}

In our paper "Predation by zooplankton on Batrachochytrium dendrobatidis: biological control of the deadly amphibian chytrid fungus?", we misidentified the species of Daphnia that consumes the chytrid fungus Batrachochytrium dendrobatidis. We reported the species to be Daphnia magna. However, it was pointed out by Joachim Mergeay that the Daphnia we used were probably of the $D$. pulicaria species complex, most likely the American lineage of D. pulex. Subsequent analysis of our Daphnia revealed that the specimens we used were indeed $D$. pulex. These were confirmed by Allison Evans of the Oregon State University Fisheries and Wildlife Department and W. Travis Godkin, an author on a major identification key of North American zooplankton (http://cfb.unh.edu/cfbkey/html/ index.html).

We give below some references used and of value for identification of Daphnia species in case they will be helpful to others.

We thank Joachim Mergeay for originally pointing out our misidentification.

The online version of the original article can be found under doi:10.1007/s10531-011-0147-4.

J. C. Buck $(\bowtie) \cdot$ A. R. Blaustein

Zoology Department, Oregon State University, 3029 Cordley Hall, Corvallis, OR 97331, USA

e-mail: buckj@science.oregonstate.edu

A. R. Blaustein

e-mail: blaustea@science.oregonstate.edu

L. Truong

Environmental and Molecular Toxicology Department, Oregon State University, 1007 ALS Building,

Corvallis, OR 97331, USA 


\section{References}

Aliberti MA, Allan E, Allard S, Bauer DJ, Beagen W, Bradt SR, Carlson B, Carlson SC, Doan UM, Dufresne J, Godkin WT, Greene S, Haney JF, Kaplan A, Maroni E, Melillo S, Murby AL, Smith JL, Ortman B, Quist JE, Reed S, Rowin T, Schmuck M, Stemberger RS (2003-2010) An image-based key to the zooplankton of the Northeast (USA), version 4.0. Center for Freshwater Biology, Department of Biological Sciences, University of New Hampshire, Durham. http://cfb.unh.edu/cfbkey/html/ index.html

Hebert PDN, Finston TL (2001) Macrogeographic patterns of breeding system diversity in the Daphnia pulex group from the United States and Mexico. Heredity 87:153-161

Pennak RW (1989) Fresh-water invertebrates of the United States, 3rd edn. Wiley, New York

Thorp JH, Covich AP (2010) Ecology and classification of North American freshwater invertebrates, 3rd edn. Academic Press, San Diego 